\title{
Nafion/Clay Hybrids with a Network Structure
}

Engin Burgaz ${ }^{1 \dagger}$, Huiqin Lian ${ }^{1,2 \dagger}$, Rafael Herrera Alonso ${ }^{1}$, Luis Estevez ${ }^{1}$, Antonios Kelarakis $^{1}$ and Emmanuel P. Giannelis ${ }^{1^{*}}$

${ }^{1}$ Department of Materials Science and Engineering, Cornell University, Ithaca, NY 14853

* To whom correspondence should be addressed. Email: epg2@cornell.edu

${ }^{\dagger}$ Both authors contributed equally to the work

${ }^{2}$ Department of Chemical Engineering and Polymer Science, Yanbian University, Yanji City, Jilin, 133002, China 


\begin{abstract}
Nafion/clay hybrid membranes with a unique microstructure were synthesized using a fundamentally new approach. The new approach is based on depletion aggregation of suspended particles - a well-known phenomenon in colloids. For certain concentrations of clay and polymer, addition of Nafion solution to clay suspensions in water leads to a gel. Using cryo-TEM we show that the clay particles in the hybrid gels form a network structure with an average cell size in the order of $500 \mathrm{~nm}$. The hybrid gels are subsequently cast to produce hybrid Nafion-clay membranes. Compared to pure Nafion the swelling of the hybrid membranes in water and methanol is dramatically reduced while their selectivity (ratio of conductivity over permeability) increases. The small decrease of ionic conductivity for the hybrid membranes is more than compensated by the large decrease in methanol permeability. Lastly the hybrid membranes are much stiffer and can withstand higher temperatures compared to pure Nafion. Both of these characteristics are highly desirable for use in fuel cell applications, since a) they will allow the use of a thinner membrane circumventing problems associated with the membrane resistance and b) enable high temperature applications.
\end{abstract}

Keywords: Depletion-Induced Interaction; Ionomer; Nafion; Nanoclay; Montmorillonite; Nanocomposite; Direct Methanol Fuel Cell 


\section{Introduction}

Polymer electrolyte membrane fuel cells (PEMFCs) are the preferred sources for various applications where both high power density and light weight are required. [1-4] Liquid fed direct methanol fuel cells (DMFCs) have an advantage over hydrogen-fed fuel cells due to a higher energy density per unit volume, existing infrastructure for fuel management, and because methanol can be produced from biomass or natural gas. [5-7] However, several challenges must be overcome before DMFCs become a competing alternative to internal combustions engines. One major drawback in DMFCs is the low oxidation kinetics of methanol at temperatures below $100^{\circ} \mathrm{C}$, which leads to low efficiencies, compared to hydrogen-fed fuel cells. [8,9] Increasing the device operation temperature would increase the electro-oxidation activity and improve the performance of DMFCs. Unfortunately, state-of-the-art electrolytes such as perfluorosulfonic acid (PFSA) polymer membranes, show a loss of performance at temperatures above $100{ }^{\circ} \mathrm{C}$ due to deterioration of mechanical performance as well as decreased conductivity. $[10,11]$ The second major drawback in conventional membranes is a high methanol crossover, which leads to depolarization of the cathode and conversion losses in terms of lost fuel. [12,13] Ideal polymer membranes should combine high ionic conductivity $(>0.1$ $\mathrm{S} / \mathrm{cm}$ ) in a wide range of temperature and hydrations conditions, low fuel permeability, mechanical robustness, chemical inertness, electrochemical stability, extended life cycle and low cost. The development of polymer electrolyte membranes with all the above requirements remains a critical challenge for advancing fuel cell technology.

Fuel cells based on Teflon-like sulfonated polymer membranes such as Nafion are currently the workhorse of the industry and serve as the benchmark for future development. [14-16] However, Nafion has a low physical strength that limits how thin the membrane can be. The conductivity of Nafion is only high when it is sufficiently hydrated, limiting the maximum operating temperature to about $80{ }^{\circ} \mathrm{C}$. Furthermore, the long-term stability of Nafion under operating conditions is not sufficient for transportation and other applications.

In an effort to circumvent some of the problems with Nafion and related membranes several groups have investigated organic/inorganic hybrid membranes. [17-20] Inorganic additives include silica, heteropolyacids, metal oxides or solid state ionic conductors, and they are incorporated in the membrane by physical mixing or they are generated in-situ using sol-gel reactions. [21-31] The expectation was that incorporation of hydrophilic inorganic particles will improve water retention and the overall performance of the composite membranes. Despite the better water retention at higher temperatures, however, the performance of cells based on heteropolyacid based hybrid membranes deteriorates over time due to acid leaching out of the membranes. In addition, the conductivity of hybrids, especially those with inorganic particles, which lack mobile protons, tends to be lower than that of unmodified membranes and becomes worse as the inorganic content increases.

Thus, despite the extensive R\&D efforts in both new polymers as well as hybrid systems, the ideal material has yet to emerge. By and large hybrid membranes investigated to date 
tend to be lacking in one or more of the properties required for practical applications including proton conductivity, permeation, swelling or mechanical stability.

In this study we describe our recent efforts to develop hybrid membranes with a unique microstructure by exploiting phase separation based on depletion aggregation - a wellknown phenomenon in colloids. Phase separation, in general, is one of the most fundamental phenomena responsible for the formation of heterogeneous structures in condensed matter. It is commonly observed in various systems including metals, semiconductors, simple liquids, and complex fluids such as polymer solutions, colloidal suspensions, emulsions, and protein solutions. [32] Colloidal suspensions, in particular, aggregate, phase separate, or form a gel, when there are strong attractive interactions between the particles. Strong attractive interactions can be generated in a colloidal suspension either by adding salt or by adding a polymer that is not absorbed by the particles (non-interacting polymer). Addition of a non-adsorbing polymer to a colloidal suspension induces interparticle depletion attractions, whose range and depth can be tuned independently by altering either the polymer's molecular weight or concentration. $[33,34]$

The theoretical framework for the depletion phenomena was first presented by Asakura and Oosawa [35] in 1954, and extended by Vrij [36] in 1976. Classic examples of depletion attraction are the creaming of latex droplets in the presence of added polymer [37] and the aggregation of red blood cells under the influence of proteins in the blood serum. [38] Application of depletion interactions to induce phase separation has raised a substantial interest in experiments [39, 40], theory [41, 42], and simulations [43, 44] over the last decades.

As mentioned earlier addition of a polymer to a colloidal suspension can induce attractive (depletion) interactions between the particles (Figure 1). These attractive interactions arise because of differences in osmotic pressure surrounding the particles. The attractive interactions can lead to particle clustering, aggregation and, in some cases, formation of a percolated network of particles, which eventually leads to gelation (Figure 2). Network formation and subsequent gelation prevents coarsening of clusters and aggregates. Eventually, the gel becomes strong enough to prevent flocculation and can potentially withstand mechanical stresses upon drying.

In this paper, we report a new approach to fabricate Nafion/clay hybrid membranes based on depletion-induced interactions between the ionomer and the clay nanoparticles. We exploit this process to fabricate new hybrid membranes with dramatically improved mechanical, swelling and barrier properties. Since Nafion is negatively charged similarly to the clay, it serves the role of the non-absorbed, non-interacting polymer. The aggregation induces a particle network formation leading to gelation. [33-35,39,40,45] Hybrid membranes obtained by casting Nafion/clay gels were evaluated in terms of ionic conductivity, methanol permeability, and mechanical properties and contrasted to those based on pure Nafion.

\section{Experimental}




\section{Materials}

Nafion (DE 1021) with a total $\mathrm{H}^{+}$exchange capacity $1.1 \mathrm{meq} / \mathrm{g}$ was obtained from IonPower as a 10 wt.\% dispersion in water. Sodium montmorillonite ( $\mathrm{Na}^{+} \mathrm{MMT}$, Cloisite $\mathrm{Na}^{+}$) with an average cation exchange capacity of $1.0 \mathrm{meq} / \mathrm{g}$ was supplied by Southern Clay Products.

Hybrids (NfMMT) were prepared by adding the required amount of sodium montmorillonite to the Nafion ${ }^{\circledR}$ solution. The mixture was first stirred at $70^{\circ} \mathrm{C}$ for $24 \mathrm{~h}$ and then left undisturbed for seven more days. Membranes were produced by casting a sample onto a Teflon mold and placing in a high-pressure chamber at $160^{\circ} \mathrm{C}$ and $160 \mathrm{psi}$ for $6 \mathrm{~h}$. Dry nitrogen was continuously fed to the chamber to maintain a constant pressure. Before testing proton conductivity and methanol permeability, the membranes were pretreated by boiling in 3 vol.\% solution of $\mathrm{H}_{2} \mathrm{O}_{2}$ for $1 \mathrm{~h}$, followed by boiling in $0.5 \mathrm{M} \mathrm{H}_{2} \mathrm{SO}_{4}$ solution for 1h, and washing twice in boiling deionized water for 1h. [46]

\section{Physical/chemical characterization}

Linear expansion ( $d \%$ ) and $\mathrm{H}_{2} \mathrm{O}$ (or methanol) uptake (W\%) were obtained using Equations. (1) and (2)

$$
\begin{aligned}
& d \%=\frac{\left(d_{1}-d_{0}\right)}{d_{0}} \\
& W \%=\frac{\left(W_{1}-W_{0}\right)}{W_{0}}
\end{aligned}
$$

$d_{0}$ and $d_{1}$ are the lengths of the membranes before and after water (or methanol) sorption, while $W_{0}$ and $W_{1}$ are the corresponding weight before and after sorption, respectively. Prior to any measuring the initial length and weight the membranes were first vacuumdried at $80^{\circ} \mathrm{C}$ for $24 \mathrm{~h}$. Then the membranes were soaked in DI water (or dry methanol) for $24 \mathrm{~h}$ at $23^{\circ} \mathrm{C}$, blotted with absorbent paper to remove any surface moisture, and weighed and measured again. [47]

Ion exchange was determined by placing the membrane in $1 \mathrm{M}$ salt solution at $80^{\circ} \mathrm{C}$ for 24h followed by titration using a $0.1 \mathrm{M} \mathrm{NaOH}$ solution with phenolphthalein as an indicator. The ion exchange capacity (IEC) was calculated based on the dry weight of the polymer.

WAXD measurements were performed on a Scintag PAD X diffractometer equipped with a $\mathrm{Cu}$ Ka source ( $1.54 \AA$ ) operating at $45 \mathrm{kV}$ and $40 \mathrm{~mA}$. Scans were made from $1.0^{\circ}$ to $30^{\circ} 2 \theta$ at a rate of $1^{\circ}$ per minute. The slits used were $1^{\circ}$ and $2^{\circ}$ for the source and $0.3^{\circ}$ and $0.5^{\circ}$ for the detector, respectively, with the wider angles closer to the sample. Low background quartz sample holders were used in all cases. 
SAXS measurements were made on a Bruker Nanostar instrument. The setup consists of a Cu $\mathrm{K}_{\alpha}$ source (1.54 $\AA$ ) operated at $40 \mathrm{kV}$ and $40 \mathrm{~mA}$. A 2D Hi-Star area detector at a sample-to-detector distance of $62.5 \mathrm{~cm}$ was used to record the scattering images. These 2D images were integrated over the azimuthal angle $(\mu)$ to obtain one-dimensional intensity versus the magnitude of the scattering vector, $q=(4 \pi / \lambda) \sin \theta$, where $\lambda$ is the $x$-ray wavelength and $2 \theta$ is the scattering angle. SAXS of gel samples was obtained using Kapton ${ }^{\circledR}$ capillary tubes sealed with epoxy on both ends.

Specimens for Cryo-Transmission Electron Microscopy (Cryo-TEM) were prepared by cryofracture by first immersing the samples into liquid propane. After immersion in liquid propane, the samples were immersed in liquid nitrogen. Samples for Cryo-TEM were microtomed in a Leica Ultracut cryo-ultramicrotome. Sections approximately 50$100 \mathrm{~nm}$ thick were cut with a Diatome diamond knife at a sample and knife temperature of $-110^{\circ} \mathrm{C}$. Cryo-TEM was performed on a Tecnai T12 TEM using an acceleration voltage of $100 \mathrm{kV}$ equipped with a proper cryo-stage specimen holder.

Dynamic mechanical analysis (DMA) was carried out on a TA Instruments DMA Q800 using the film/fiber tension clamp. The response as a function of temperature was measured by subjecting a rectangular film to a temperature swing from $32^{\circ} \mathrm{C}$ to $250^{\circ} \mathrm{C}$ at a rate of $5^{\circ} \mathrm{C} / \mathrm{min}$. Before measurement, the samples were dried for $24 \mathrm{~h}$ in air at $80^{\circ} \mathrm{C}$.

Tensile tests were performed at room temperature with an Instron 5500 Mechanical Tester at constant strain rate of $1 \mathrm{~mm} / \mathrm{min}$ following standard ASM protocols.

Ionic conductivity was measured at room temperature in a closed vessel under a controlled relative humidity (RH) environment. The relative humidity inside the chamber was controlled with different saturated salt solutions and measured with a Fisherbrand Traceable Digital Humidity/Temperature Meter. [48] A cell, equipped with a window to allow rapid equilibration, was used to measure ionic conductivity. [49] The resistance of the membrane was measured by AC impedance spectroscopy (HP 4192A, LF Impedance Analyzer) using a frequency range of $5 \mathrm{~Hz}$ to $13 \mathrm{MHz}$ and an amplitude of $10 \mathrm{mV}$. A twopoint probe was used. The resistance of the membrane was calculated from the intercept of the real axis in the intermediate frequency domain of the impedance spectrum. Conductivity, $\sigma$ was calculated from

$$
\sigma=\frac{d}{l w R}
$$

where $d$ is the distance between the two platinum electrodes, $l$ and $w$ are the thickness and width of the membrane, respectively, and $R$ is the measured resistance of the membrane.

A glass cell with two-compartments (source, A, and receiving, B) separated by the membrane was obtained from PermeGear, Inc to measure methanol permeability. Compartment $(A)$ was filled with a $2.0 \mathrm{M}$ solution of methanol in deionized water while the receiving compartment $(B)$ was filled with deionized water. The methanol concentration that was transported through the membrane was determined by sampling a 
small amount of the solution from compartment $B$ at $25^{\circ} \mathrm{C}$ by gas chromatography. Methanol permeability was determined using the following equation [50,51]

$$
C_{B}(t)=\frac{A C_{A}}{V_{B}} \frac{D \cdot K}{l}\left(t-t_{0}\right)=P \frac{A C_{A}}{V_{B} l}\left(t-t_{0}\right)
$$

where $A$ and $l$ are the membrane area and thickness, $D$ and $K$ are the methanol diffusion coefficient and partition coefficient between the membrane and the adjacent solution, $C_{\mathrm{A}}$ and $C_{\mathrm{B}}$ are the concentrations of methanol in compartment $(A)$ and $(B)$, respectively, and $V_{B}$ is the volume of the compartment $(B)$. $D$ was assumed constant throughout the membrane and $K$ independent of concentration. $P$ is the membrane permeability, defined as the product $D \cdot K$. The term $t_{0}$ is termed time lag, and is explicitly related to the diffusion coefficient, $t_{0}=l^{2} / 6 D$. [51] By measuring $C_{\mathrm{B}}$ as a function of time, the methanol permeability can be calculated from the slope of the curve. $C_{\mathrm{B}}$ was monitored during a typical $2 \mathrm{~h}$ period, where every 20 min a sample of $10 \mu \mathrm{l}$ was drawn from compartment $(B)$. The concentration of methanol for each sample drawn was measured 3 times by injecting $1 \mu \mathrm{l}$ through a GC using a microsyringe (Hamilton 84875). A GC equipped with a Flame Ionization Detector (GC-FID, HP 5890) and a Supelcowax-10 fused silica capillary column (60m x $0.53 \mathrm{~mm}$ i.d., $0.5 \mu \mathrm{m}$ films thickness; Supelco Inc.) was used.

\section{Results and Discussion}

The phase diagram of Nafion-montmorrilonite in water is shown in Figure 3. The dividing line separates samples that form a gel from those that remain either in suspension or flocculate and phase separate. Samples with either a relatively high concentration of polymer or clay lead to a gel. Since the clay particles and Nafion are both negatively charged, the requirement for a non-interacting polymer and, thus, for depletion aggregation is satisfied. Polymer chains with an affinity to the clay tend to either intercalate in the clay galleries or otherwise be absorbed on the external surfaces of the clay particles leading in both cases to clay particle flocculation.

An alternate polymer-clay interaction mechanism has been proposed for similar systems that considers an initial attachment of a negatively charged macromolecule to the positively charged clay edge (e.g. clay counterions offer effective bridging between organic-inorganic surface) and a subsequent diffusion of the polymer within the clay galleries [52]. That kind of mechanism might well take place to some extent in the present system, although the lack of any organophilic modification of the clay used here certainly does not promote polymer migration to the intergallary space, particularly under anhydrous conditions

The gelation is related to the mechanism of layer aggregation in clays. A typical suspension of clay particles should consist of laminated aggregates along with delaminated areas. Clay suspensions even in the absence of a polymer are known to form a gel primarily through edge-to-face interactions. As Figure 3 suggests gelation can also take place by adding Nafion. Addition of Nafion leads to either flocculation as the laminated face-to-face aggregates grow in size or gelation, promoted by several edge-toface interactions (Figure 4). Figure 5 are cryo-TEM images of a clay-Nafion gel before 
any drying. Thin face-to-face aggregates composed only of a few layers are connected with each other into a network structure via several edge-to-face interactions.

The WAXD patterns for Nafion clay gels are shown in Figure 6. The WAXD pattern of a suspension of $\mathrm{Na}^{+}$montmorillonite is included for comparison. The latter shows two diffraction peaks with d-spacing of 1.25 and $1.54 \mathrm{~nm}$ corresponding to clay intercalated with one and two layers of water, respectively. Those peaks are nearly absent from the Nafion hybrid gels containing up to 23 wt. \% clay suggesting that stacking of the clay layers in the gels, if at all present, is very disordered (Figure 6a). For easy comparisons the clay content is expressed on a dry membrane basis. Hybrid gels containing higher amounts of clay (33 - $80 \%$ ) show virtually the same diffraction pattern as the $\mathrm{Na}^{+}$ montmorillonite sample (Figure 6b), where clay laminates predominate.

The SAXS patterns for Nafion hybrid gels are shown in Figure 7. The pattern of pure Nafion is also included for comparison. The diffraction peak at $q=0.043 \AA^{-1}(d=14.7$ $\mathrm{nm}$ ) has been attributed to ionic group clustering in Nafion. As the water content increases this peak shifts to smaller q values and its intensity increases due to swelling that takes place in aqueous solutions. [53, 54] In the hybrid gels the ionic domain peak shifts to lower $q$ values suggesting that the ionic domains get larger. The $q$ values for samples containing 23,33 and $38 \mathrm{wt} . \%$ clay are $0.036,0.029$ and $0.037 \AA^{-1}$, respectively. The corresponding $d$ values are 17.6, 21 and $16.9 \mathrm{~nm}$, respectively. The width of the peak for the 23 and 38 wt.\% clay gels suggests that there might be more than one characteristic size for the domains: one with a size similar to that of the domains in Nafion and another with a larger (swollen) size.

A series of composite membranes were prepared by casting hybrid gels at $160^{\circ} \mathrm{C}$ and 160 psi for $6 \mathrm{~h}$ and characterized. Since surface tension forces present under drying (at conditions far away from the supercritical point of water) provide a mechanism for particle aggregation and reorganization, some of the network microstructure is expected to be lost upon processing. Figure 8 is a TEM micrograph of a hybrid membrane after the high pressure/high temperature processing of the gel precursor. Clearly more face-toface aggregation is present at the expense of edge-to-face aggregates seen in the gels. Indeed the WAXD pattern of the sample containing 23 wt.\% clay (Figure 9) shows a strong diffraction peak corresponding to stacks of clay layers intercalated with a monolayer of water. The peak in the WAXD pattern at low angles corresponds to the ionic domains. The peak for the ionic domains in the hybrids shifts to lower angles (higher spacing) compared to the pure Nafion. Additionally the peak corresponding to the ionic domains is quite broad suggesting that there might be more than one size domain present in the hybrid membranes in agreement with the SAXS data discussed above. We showed earlier that small amounts of clay to Nafion lead to a significant shrinkage of the ionic domains of the casted membranes [55]. The fact that in the present study the ionic domains of the nanocomposites are found to expand rather than shrink points out to major rearrangements of Nafion superstructure induced by the percolated nature of the precursor gel. It seems reasonable to assume that such a reorganization includes (although not limited to) merging of smaller ionic domains towards larger structures. 
At higher angles, the XRD patterns are governed by the diffraction signal of crystalline Nafion. Following standard peak fit procedures, each diffraction signal can be deconvoluted into a broad amorphous halo and a sharper crystalline component (data not shown here). It was found that introduction of nanoclay does not affect the crystallinity index $\left(\mathrm{x}_{\mathrm{c}}\right)$ of Nafion, that remains close to $\mathrm{x}_{\mathrm{C}}=0.19$.

The swelling data in water and methanol are summarized in Table 1 . The values provided in Table 1 are averages of two measurements. In contrast to pure Nafion, the hybrid membranes swell much less in either water or methanol. Pure Nafion swells significantly in both methanol and water. The weight gain of pure Nafion in methanol is about $275 \%$. Both swelling and weight gain decrease in the hybrid membranes. In the case of $\mathrm{MeOH}$ a decrease by a factor of 8 is observed. The decrease does not seem to be proportional to the amount of clay in the nanoparticles suggesting that the microstructure of the nanoparticles also plays a significant role. In particular, a pronounced minimum of the solvent retention was observed at $14-17$ wt.\% loading. This effect can be attributed to the compact microstructure of the hybrids that imposes (mechanical) constrains to solvent absorption. At the same time, clay nanoparticles can also act as robust structural boundaries, limiting the accessibility of Nafion ionic domains to solvent molecules. Further addition of nanofiller leads to more swelling most likely due to the disruption of the clay network at higher clay loadings.

The DMA of hybrid membranes is shown in Figure 10. It has been long realized that Nafion shows two principal relaxations that has been originally explained within the concept of a dual glass transition for Nafion [56]. Recent systematic investigations by means of dielectric spectroscopy, DMA, ${ }^{19} \mathrm{~F}$ solid state NMR and SAXS enabled a revised interpretation of Nafion local and global dynamics [54,57-59]. First, the low temperature $\beta$ relaxation has been assigned to the genuine glass transition of Nafion, given that it is directly related to the onset of long range segmental mobility of Nafion main chain, without disturbing the electrostatic characteristics of the overall superstructure. Second, the high temperature $\alpha$ relaxation has been attributed to the onset of long range mobility of both main chain and side chain giving rise to the gradual collapse of the static network and the subsequent evolution of a dynamic network.

Consistent with previous reports pure Nafion shows a high temperature $\alpha$ transition at around $125^{\circ} \mathrm{C}$. The low temperature $\beta$ transition is outside the temperature range measured. In contrast, the hybrid membranes show two different relaxations between $75^{\circ} \mathrm{C}$ and $250^{\circ} \mathrm{C}$. The first one is rather weak and it appears at $75^{\circ}$ and $120^{\circ} \mathrm{C}$ for the nanocomposites containing 14, 23 and 17 wt.\%, respectively. The second relaxation appears around $230^{\circ} \mathrm{C}$ for all hybrids and it is much stronger. It has been reported that the $\mathrm{Na}^{+}$-form of Nafion shows a distinct $\alpha$ (ca. $240{ }^{\circ} \mathrm{C}$ ) and weak $\beta$ (ca. $150^{\circ} \mathrm{C}$ ) relaxation. [60] Also neutralization of Nafion with a range of alkali metal ions $\left(\mathrm{Na}^{+}, \mathrm{K}^{+}\right.$, $\mathrm{Rb}^{+}, \mathrm{Cs}^{+}$) shows little change in the $\alpha$ and $\beta$ relaxation temperatures. [57] A partial ion exchange reaction between the Nafion and the $\mathrm{Na}^{+}$-clay leading to the formation of the $\mathrm{Na}^{+}$-form of Nafion might account for the shift to higher temperature. To further evaluate the origin of the temperature shift we tested a hybrid membrane after acid treatment. 
While the relaxation shifts to a somewhat lower temperature still the transition occurs at $160^{\circ} \mathrm{C}$, which is much higher than that observed for pure Nafion. Therefore, the profound displacement and suppression of $\alpha$-relaxation tan $\delta$ peak observed for all hybrids can be directly related to the molecular confinement in the vicinity of polymer-clay interface that drastically hinders the polymer chain motions.

In addition to the temperature shift, the hybrids show dramatic increases in modulus (Figure 10a). For example, the sample containing $23 \mathrm{wt} . \%$ clay shows a storage modulus about 10 times that of Nafion. The overall DMA analysis reveals that the hybrid membranes are much stiffer and can withstand higher temperatures compared to pure Nafion. Both of these characteristics are highly desirable for use in fuel cell applications. A higher modulus membrane might allow the use of a thinner membrane circumventing problems associated with the membrane resistance. Additionally, the mechanical strength at high temperature enables application requiring temperatures in excess of 100 ${ }^{\circ} \mathrm{C}$.

Consistent with the DMA measurements the tensile tests at room temperature (Figure 11) showed much higher values of Young modulus for nanocomposites membranes, while the elongation at break systematically decreased with filler loading, indicating a more brittle response of the hybrids.

Figure 12 shows the ionic conductivity of pure and hybrid Nafion membranes as a function of the relative humidity $(\mathrm{RH})$. In the specific configuration employed here, the conductivity measured is a combination of both normal (through-plane) and transverse (in plane) direction and thus we cannot rule out any anisotropy for the conductivity of nanocomposites. The hybrid membranes follow a similar trend to the pure Nafion; the conductivity decreases as the RH decreases. The difference in conductivity between Nafion and the hybrid membranes becomes progressively larger as the RH decreases. Clays are known to loose conductivity much faster than pure Nafion as the hydration decreases contributing to this behavior. [61]

Figure 13a shows the methanol concentration at the permeate cell measured for neat Nafion and $23 \mathrm{wt} \%$ clay as a function of time. Figure 13b shows the relative permeability $\left(P / P_{o}\right)$ of methanol for Nafion and the hybrid membranes as a function of clay loading. The permeability of the hybrid membrane containing $23 \mathrm{wt}$ \% decreases by more than a factor of three compared to the neat Nafion. A selectivity $(\kappa)$ term can be defined as:

$$
\kappa=\frac{\sigma}{P}
$$

This selectivity term is proportional to the ratio of ionic conductivity to methanol permeability of the membrane. Higher values for selectivity are preferable. Figure 14 shows the selectivity parameters $\left(\kappa_{\mathrm{NfMMT}}\right)$ for different hybrid membranes relative to Nafion. The selectivity of Nafion ( $\left.\kappa_{\text {Nafion }}\right)$ is set to one. Based on this analysis, the hybrid membrane containing $23 \mathrm{wt}$ \% clay shows the best selectivity, mainly due to its lowest methanol permeability. The small decrease of ionic conductivity for the hybrid membrane is more than compensated by the large decrease in methanol permeability. 
Selectivity values from 2-7 have been reported for block, graft and random copolymer electrolytes. However, Deluca et al. have raised concerns about the stability and durability of those systems [16]. We previously reported selectivity increases by a factor of five for clay nanocomposites based on $\mathrm{H}^{+}$-exchanged clays and measured under identical conditions [55]. We attribute the differences to the different counterions present in the clay used in the nanocomposites.

\section{Conclusions}

In summary Nafion/clay hybrid membranes with a unique microstructure were synthesized using a fundamentally new approach. The new approach is based on depletion aggregation of suspended particles - a well-known phenomenon in colloids. Using cryo-TEM we show that the clay particles in the hybrid gels form a network structure with an average cell size of $500 \mathrm{~nm}$. Hybrid membranes cast from hybrid gels show significant property improvements compared to pure Nafion. Compared to pure Nafion the swelling of the hybrid membranes in water and methanol is dramatically reduced while their selectivity (ratio of conductivity over permeability) increases. The small decrease of ionic conductivity for the hybrid membranes is more than compensated by the large decrease in methanol permeability. Lastly the hybrid membranes are much stiffer and can withstand higher temperatures compared to pure Nafion. Both of these characteristics are highly desirable for use in fuel cell applications, since they might allow the use of a thinner membrane circumventing problems associated with the membrane resistance as well as enable high temperature applications.

\section{Acknowledgments}

We acknowledge the financial support of the Cornell Fuel Cell Institute funded by DOE. EPG acknowledges the support of Award No. KUS-C1-018-02, made by King Abdullah University of Science and Technology (KAUST). 


\section{References}

[1] Rikukawa M, Sanui K. Prog Polym Sci 2000;25(10):1463-1502.

[2] Hamrock SJ, Yandrasits MA. Polym Rev 2006;46(3):219-244.

[3] Dohle H, Divisek J, Mergel J, Oetjen HF, Zingler, C., Stolten, D. J Power Sources 2002;105(2):274-282.

[4] Guraua B, Smotkin ES. J Power Sources 2002;112(2):339-352.

[5] Carrette L, Friedrich KA, Stimming U. Chemphyschem 2000;1(4):162-193.

[6] Li X, Roberts EPL, Holmes SM, Zholobenko V. Solid State Ionics 2007;178(1920):1248-1255.

[7] Neburchilov V, Martin J, Wang HJ, et al. J Power Sources 2007;169(2):221-238.

[8] Wasmus S, Kuver A. J Electroanal Chem 1999;461(1-2):14-31.

[9] Ren XM, Springer TE, Zawodzinski TA, Gottesfeld S. J Electrochem Soc 2000;147(2):466-474.

[10] Li QF, He RH, Jensen JO, et al. Chem Mater 2003;15(26):4896-4915.

[11] Hogarth WHJ, da Costa JCD, Lu GQ. J Power Sources 2005;142(1-2):223-237.

[12] Heinzel A, Barragan VM. J Power Sources 1999;84(1):70-74.

[13] Ren XM, Zelenay P, Thomas S, Davey J, Gottesfeld S. J Power Sources 2000;86(12):111-116.

[14] Smitha B, Sridhar S, Khan AA. J Membr Sci 2005;259(1-2):10-26.

[15] Saito M, Tsuzuki S, Hayamizu K, Okada T. J Phys Chem B 2006;110(48): 2441024417.

[16] Deluca NW, Elabd YA. J Polym Sci Part B Polym Phys 2006;44(16):2201-2225.

[17] Jannasch P. Curr Opin Colloid Interface Sci 2003;8:(1):96-102.

[18] He XC, Tang HL, Pan M. J Appl Polym Sci 2008;108(1):529-534.

[19] Nagarale RK, Gohil GS, Shahi VK, et al. Macromolecules 2004;37:(26):1002310030. 
[20] Zhang W, Li MKS, Yue P-L, Gao P. Langmuir 2008; 24(6): 2663-2670.

[21] Chen Z, Holmberg B, Li W, Wang X, Deng W, Munoz R, Yan Y. Chem. Mater 2006;18(24): 5669-5675.

[22] Adjemian KT, Dominey R, Krishnan L, Ota H, Majsztrik P, Zhang T, et al. Chem Mater 2006; 18(9):2238-2248.

[23] Truffler-Boutry D, De Geyer A, Guetaz L, et al. Macromolecules 2007;40(23):82598264.

[24] Thomassin JM, Pagnoulle C, Caldarella G, et al. Polymer 2005;46(25):1138911395.

[25] Ladewig BP, Knott RB, Hill AJ, et al. Chem Mater 2007;19(9):2372-2381.

[26] Rhee CH, Kim HK, Chang H, Lee JS. Chem Mater 2005;17(7):1691-1697.

[27] Pereira F, Valle K, Belleville P, Morin A, Lambert S, Sanchez C. Chem Mater 2008;20(5):1710-1718.

[28] Satterfield MB, Majsztrik PW, Ota H, Benziger JB, Bocarsly AB. J Polym Sci Part B Polym Phys 2006;44(16):2327-2345.

[29] Tang H, Wan Z, Pan M, Pan M, Jiang SP. Electrochem Commun 2007;9(8):20032008.

[30] Tasaki K, Gasa J, Wang HB, DeSoussa R. Polymer 2007;48(15):4438-4448.

[31] Li CN, Sun GQ, Ren SZ, et al. J Membr Sci 2006;272(1-2):50-57.

[32] Onuki A. Phase transition dynamics. Cambridge: Cambridge University Press; 2002.

[33] Anderson VJ, Lekkerkerker HNW. Nature 2002; 416(6883):811-815.

[34] Poon WCK. J Phys Condens Matter 2002;14(33):R859-R880.

[35] Asakura S, Oosawa F. J Chem Phys 1954;22(7):1255-1256.

[36] Vrij, A. Pure Appl Chem 1976;48(4):471-483.

[37] Tanaka H, Nishikawa Y, Koyama T. J Phys Condens Matter 2005;17(5):L143-L153.

[38] Neu B, Meiselman HJ. Langmuir 2001;17(26):7973-7975. 
[39] Lu PJ, Zaccarelli E, Ciulla F, et al. Nature 2008;453(7194):499-U4.

[40] Manley S, Wyss HM, Miyazaki K, et al. Phys Rev Lett 2005;95(23):208302.

[41] Fuchs M, Schweizer KS. Europhys Lett 2000;51(6):621-627.

[42] Aarts DGAL, Tuinier R, Lekkerkerker HNW. J Phys Condens Matter 2002;14(33): 7551-7561.

[43] Dijkstra M, van Roij R, Evans R. Phys Rev E 1999;59(5):5744-5771.

[44] Bolhuis PG, Louis AA, Hansen JP. Phys Rev Lett 2002;89(12):128302.

[45] Stradner A, Sedgwick H, Cardinaux F, et al. Nature 2004;432(7016):492-495.

[46] Adjemian KT, Lee SJ, Srinivasan S, Benziger J, Bocarsly AB. J Electrochem Soc 2002;149:A256-A261.

[47] Walker CW. J Electrochem Soc 2004; 151(11): A1797-A1803.

[48] Dean JA, Lange NA, Knovel (Firm) Lange's handbook of chemistry. McGraw-Hill: New York, 1999.

[49] Zawodzinski TA, Neeman M, Sillerud LO, Gottesfeld S. J Phys Chem 1991; 95(15): 6040-6044.

[50] Crank J. The mathematics of diffusion; 2nd ed. Clarendon Press: Oxford, 1975.

[51] Tricoli V, Carretta N, Bartolozzi M. J Electrochem Soc 2000;147(4):1286-1290.

[52] Chisholm BJ, Moore RB, Barber G, Khouri F, Hempstead A, Larsen M, lson E, Kelley J, Balch G, Caraher J. Macromolecules 2002;35(14):5508-5516.

[53] Gebel G. Polymer 2000;41(15):5829-5838.

[54] Mauritz KA, Moore RB. Chem Rev 2004;104(10):4535-4585.

[55] Alonso R H, Estevez L, Lian H, Kelarakis A, Giannelis EP. Polymer, in print.

[56] Kyu T, Eisenberg A, Perfluorinated Ionomer Membranes, in: A.Eisenberg, H.L. Yeager (Eds.), ACS Symposium Series 180, American Chemical Society, Washington, DC, 1982.

[57] Page KA, Cable KM, Moore RB Macromolecules 2005;38(15):6472-6484.

[58] Obsorn SJ, Hassan MK, Divoux GM, Rhoades DW, Mauritz KA, Moore RB Macromolecules 2007;40(10):3886-3890. 
[59] Page KA, Jarrett W, Moore RB J Polym Sci Part B: Polym Phys 2007;45:21772186.

[60] Cable KM. Ph.D. Thesis. The University of Southern Mississippi: Hattiesburg, 1996.

[61] Aliouane N, Hammouche A, De Doncker RW, Telli L, Boutahala M, Brahimi B. Solid State Ionics 2002;148(1-2):103-110 
List of Tables:

Table 1. Swelling Data of Nafion and Nafion-clay Hybrid Membranes 
List of Figures:

Figure 1. Schematic showing a suspension of spherical nanoparticles in the absence (a) and in the presence (b) of a non interacting polymer. In the first case the particles form a stable suspension. In the latter case, strong attractive interactions between the particles can be generated in the presence of a non-adsorbing polymer (i.e. a polymer that is not absorbed by the particles).

Figure 2. Schematic showing the evolution from individual nanoparticles (a) to isolated clusters (b) to a percolated network (c).

Figure 3. Phase diagram for the Nafion-clay system in water. Filled symbols represent gel samples. Samples that have not led to a gel (sols) are shown with non-filled symbols.

Figure 4. Schematic representing clay-polymer systems: face-to-face aggregation (top) and edge-to-face aggregation (bottom)

Figure 5. Cryo-TEM of Nafion-clay hybrids gels before any drying

Figure 6. WAXD of Nafion-clay hybrid gels before drying

Figure 7. SAXS of Nafion-clay hybrid gels before drying

Figure 8. TEM micrograph of 23 wt.\% clay hybrid membrane after casting

Figure 9. WAXD of Nafion-clay hybrid membranes

Figure 10. DMA of Nafion and Nafion- clay hybrid membranes: a) Storage modulus as a function of temperature and b) tan $\delta$ as a function of temperature

Figure 11. Stress-strain curves of Nafion and 23 wt\% clay-Nafion membranes.

Figure 12. Ionic conductivity vs. relative humidity [\% RH] for Nafion and Nafion clay hybrid membranes

Figure 13. a) Methanol concentration (wt.\%) at the permeate cell as a function of time for pure Nafion and 23wt\% nanocomposite membranes.

b) Relative Permeability of Nafion and Nafion-clay hybrid membranes

Figure 14. Relative Selectivity of Nafion and Nafion-clay hybrid membranes 


\section{Table 1 Swelling Data of Nafion and Nafion-clay Hybrid Membranes}

\begin{tabular}{|c|c|c|c|c|}
\hline & Nafion & 14 wt.\% clay & 17 wt.\% clay & 23 wt.\% clay \\
\hline $\begin{array}{c}\text { Water Swelling } \\
\left(\mathrm{d} / \mathrm{d}_{0}, \%\right)\end{array}$ & 22 & 7 & 13 & 13 \\
\hline $\begin{array}{c}\text { Water Absorption } \\
\left(\mathrm{W} / \mathrm{W}_{0} \%\right)\end{array}$ & 7 & 2 & 4 & 6 \\
\hline $\begin{array}{c}\text { MeOH Swelling } \\
\left(\mathrm{d} / \mathrm{d}_{0}, \%\right)\end{array}$ & 111 & 46 & 16 & 93 \\
\hline $\begin{array}{c}\text { MeOH Absorption } \\
\left(\mathrm{W} / \mathrm{W}_{0}, \%\right)\end{array}$ & 275 & 33 & 35 & 59 \\
\hline
\end{tabular}


a
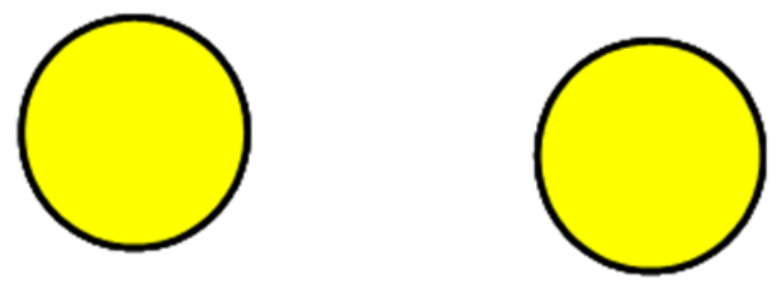

b

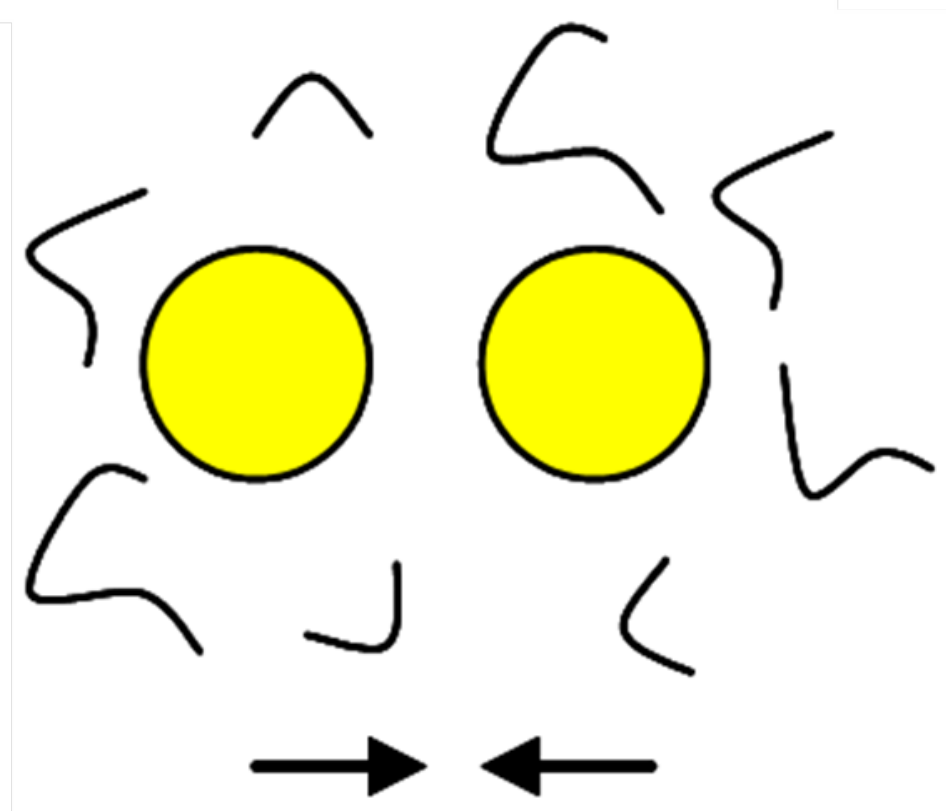

Figure 1. Schematic showing a suspension of spherical nanoparticles in the absence (a) and in the presence (b) of a non interacting polymer. In the first case the particles form a stable suspension. In the latter case, strong attractive interactions between the particles can be generated in the presence of a non-adsorbing polymer (i.e. a polymer that is not absorbed by the particles). 


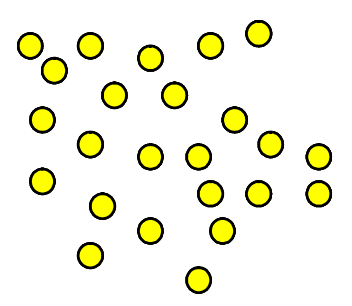

a

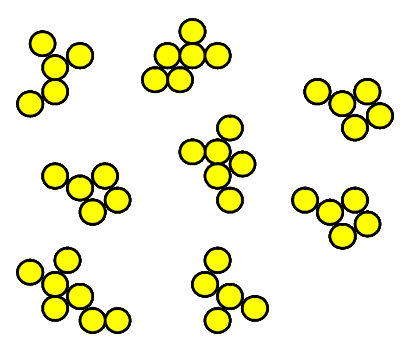

b

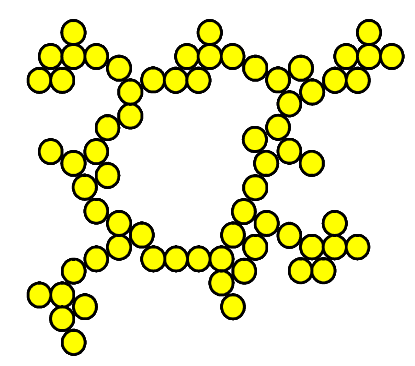

C

Figure 2. Schematic showing the evolution from individual nanoparticles (a) to isolated clusters (b) to a percolated network (c). 


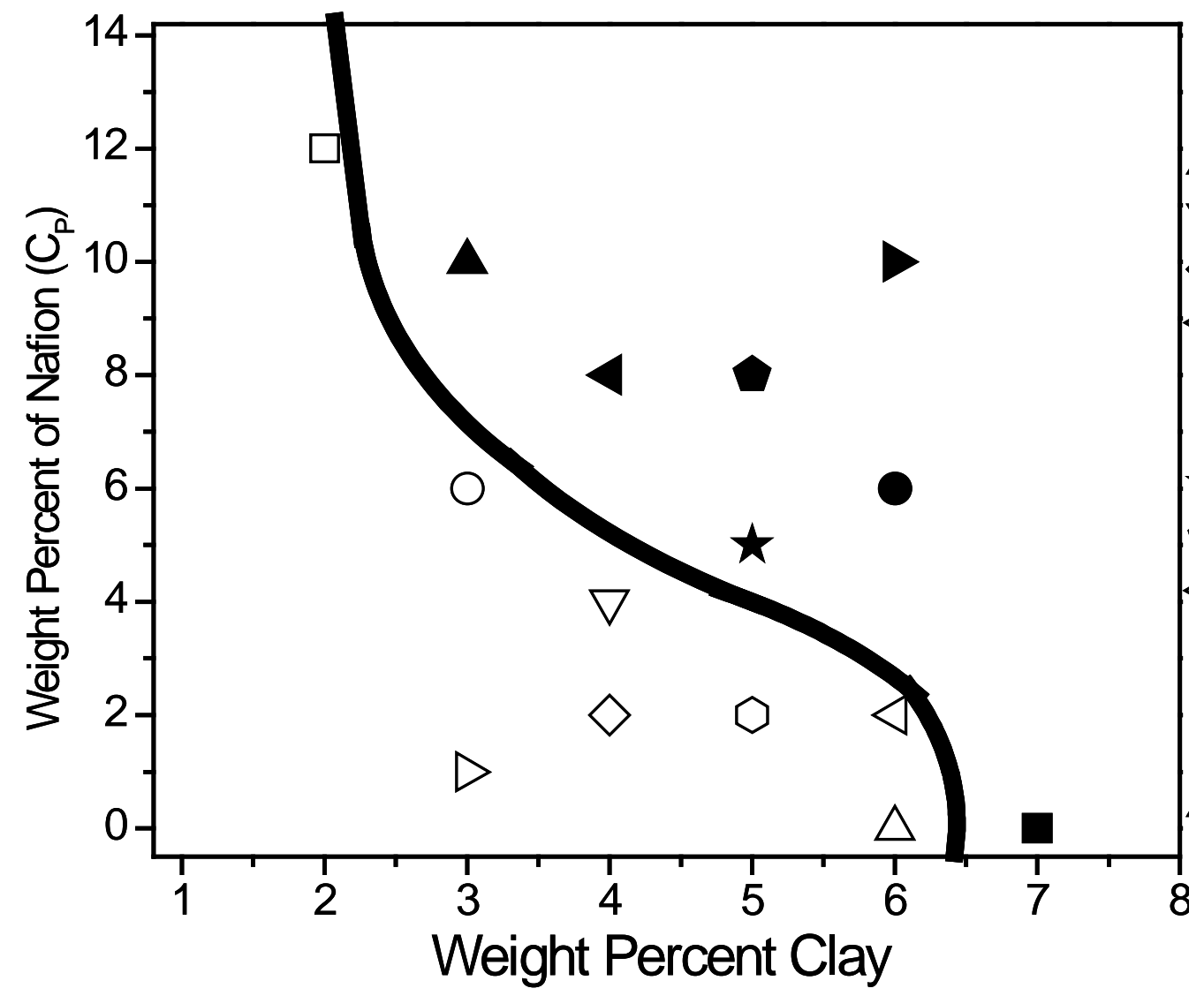

Figure 3. Phase diagram for the Nafion-clay system in water. Filled symbols represent gel samples. Samples that have not led to a gel (sols) are shown with non-filled symbols. 

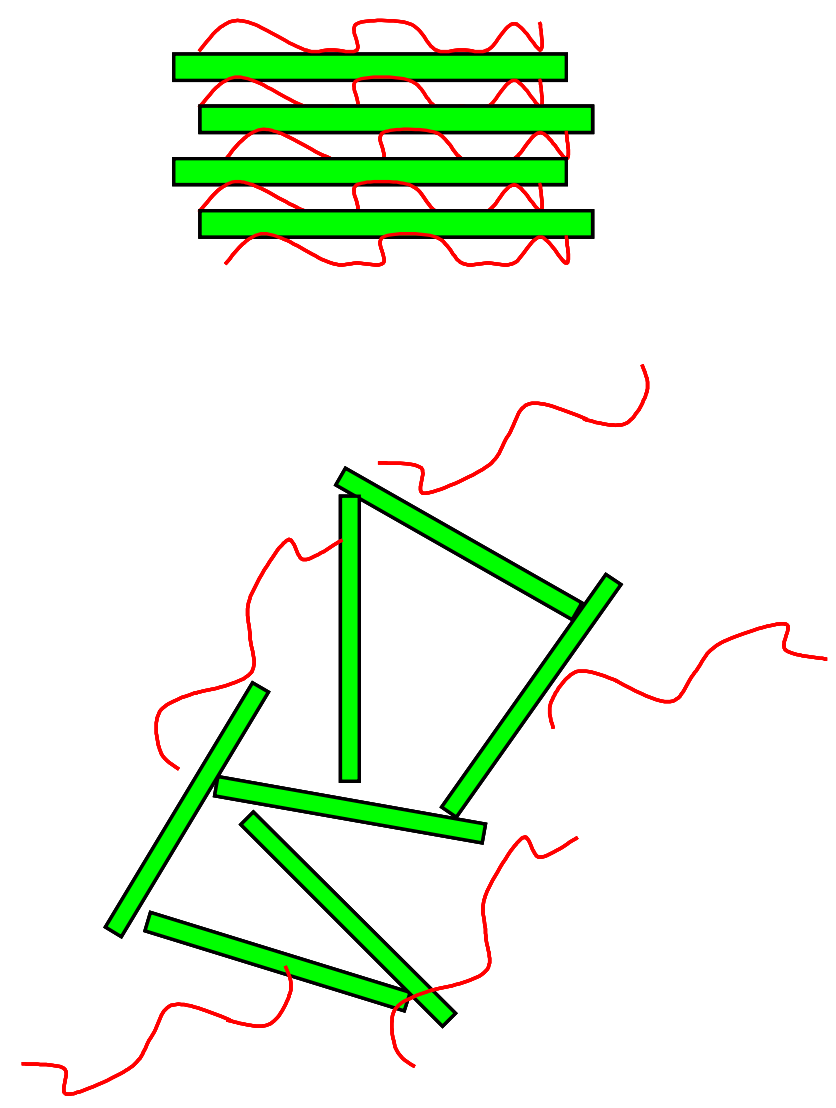

Figure 4. Schematic representing clay-polymer systems: face-to-face aggregation (top) and edge-to-face aggregation (bottom) 

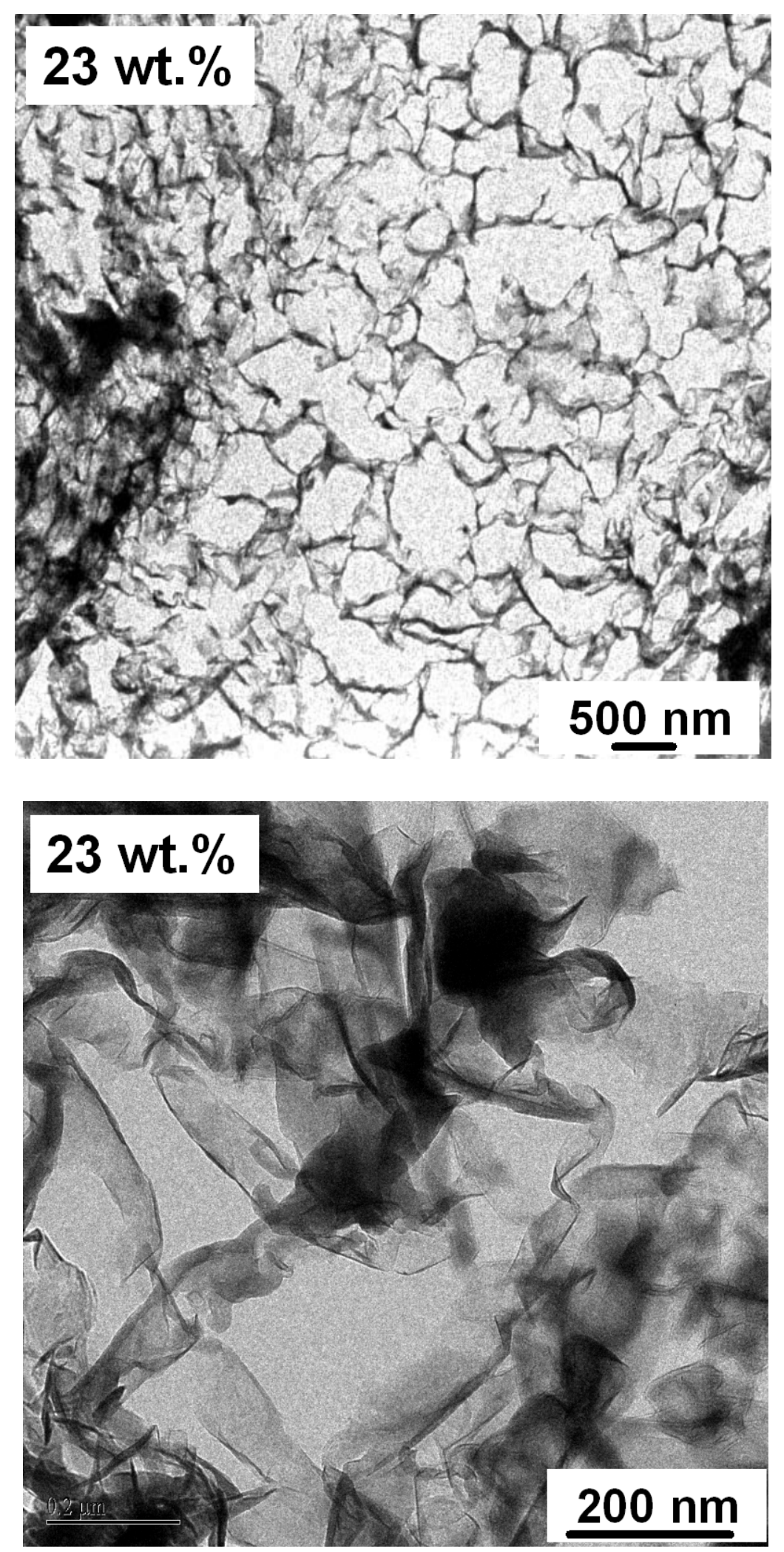

Figure 5. Cryo-TEM of Nafion-clay hybrids gels before any drying 

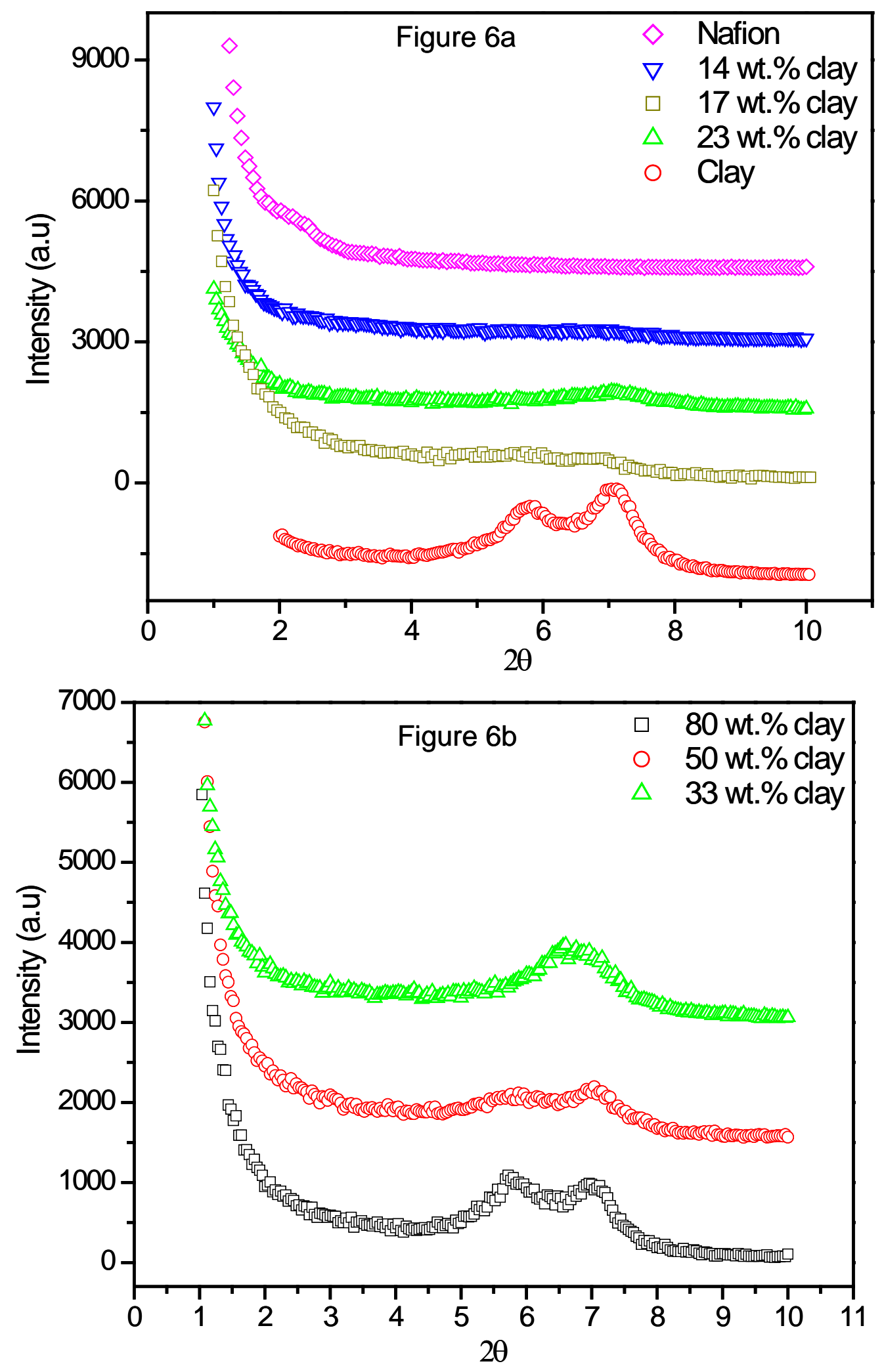

Figure 6. WAXD of Nafion-clay hybrid gels before drying 


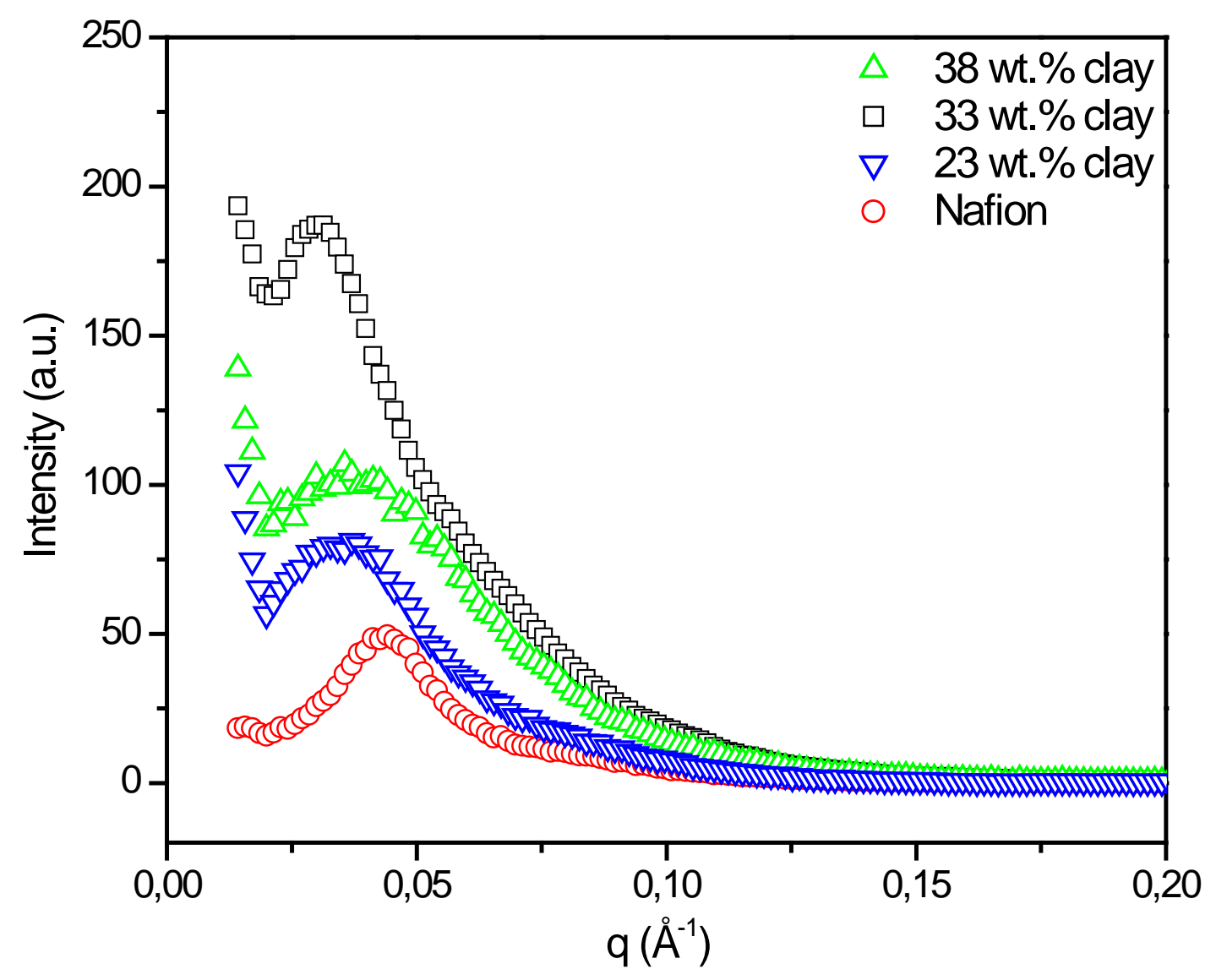

Figure 7. SAXS of Nafion-clay hybrid gels before drying 


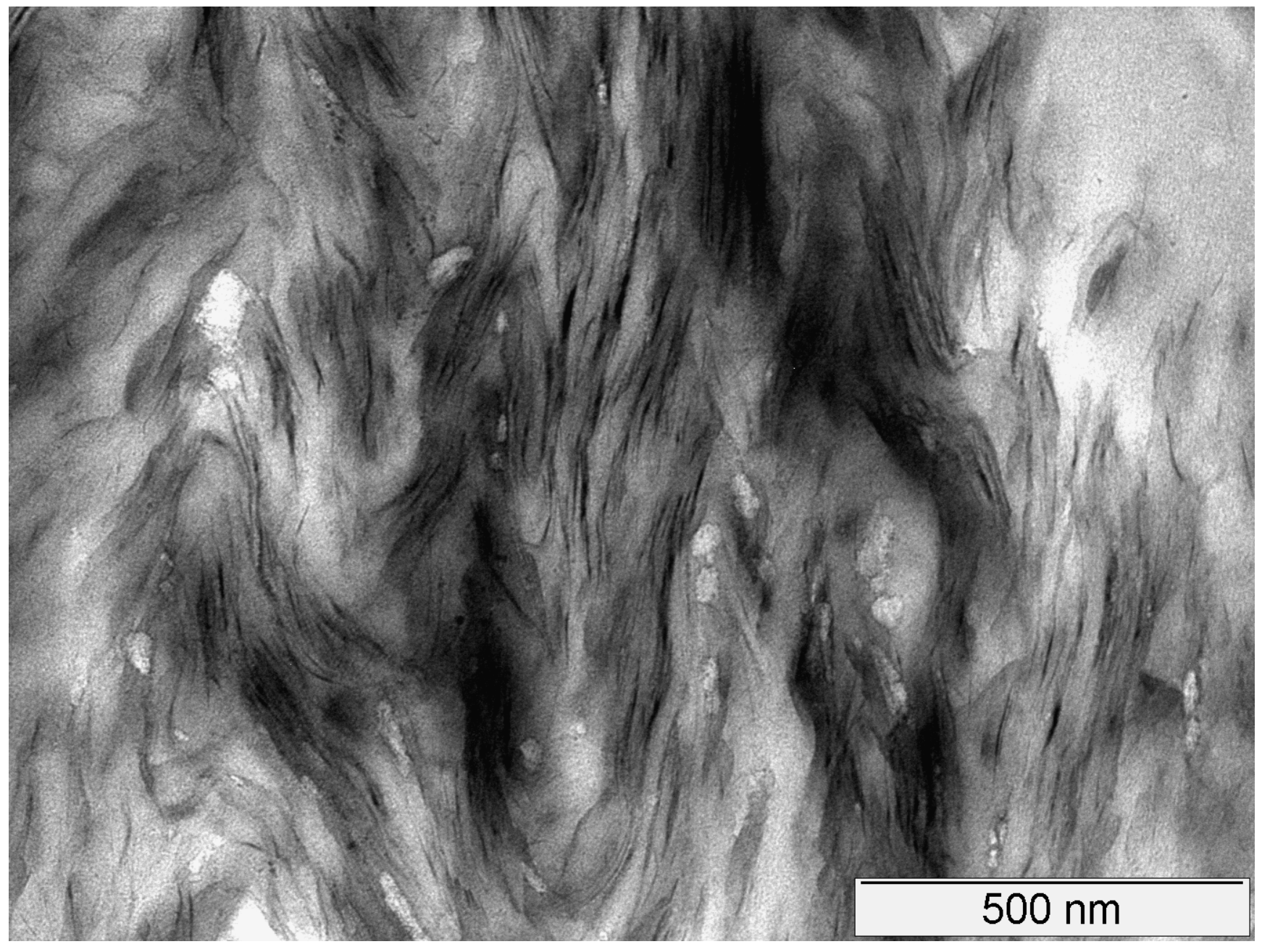

Figure 8. TEM micrograph of 23 wt.\% clay hybrid membrane after casting 


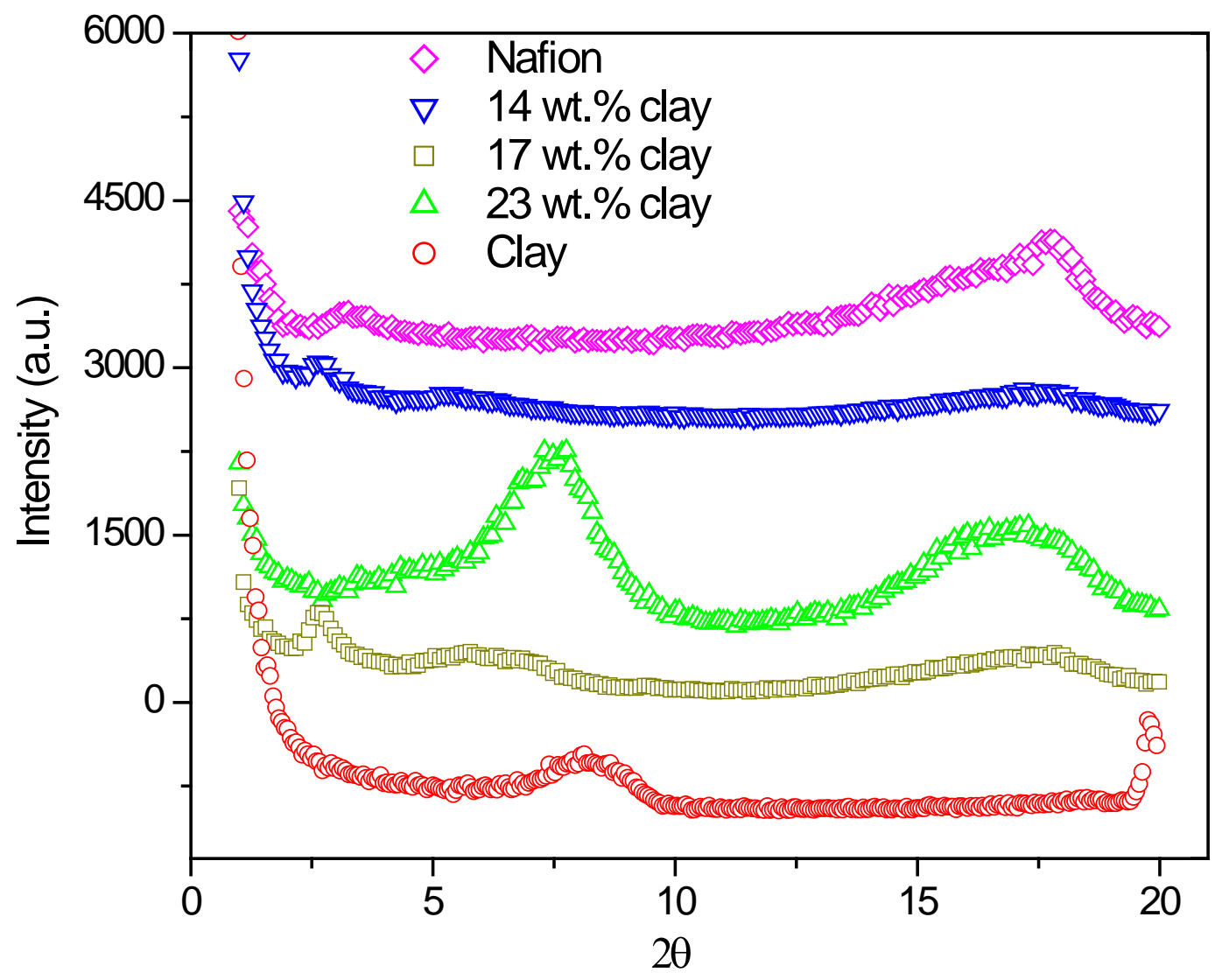

Figure 9. WAXD of Nafion-clay hybrid membranes 

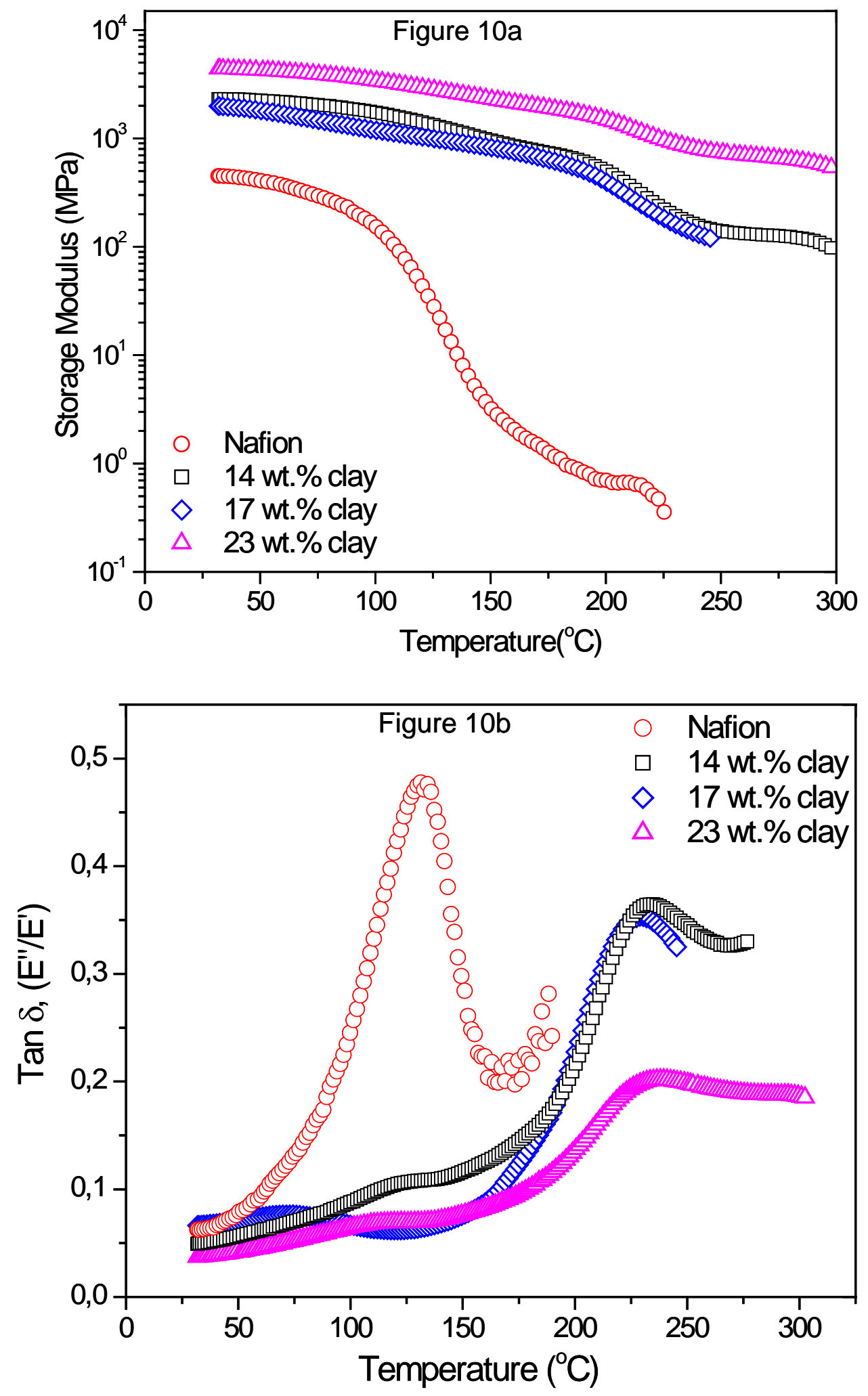

Figure 10. DMA of Nafion and Nafion- clay hybrid membranes: a) Storage modulus as a function of temperature and $b$ ) $\tan \delta$ as a function of temperature 


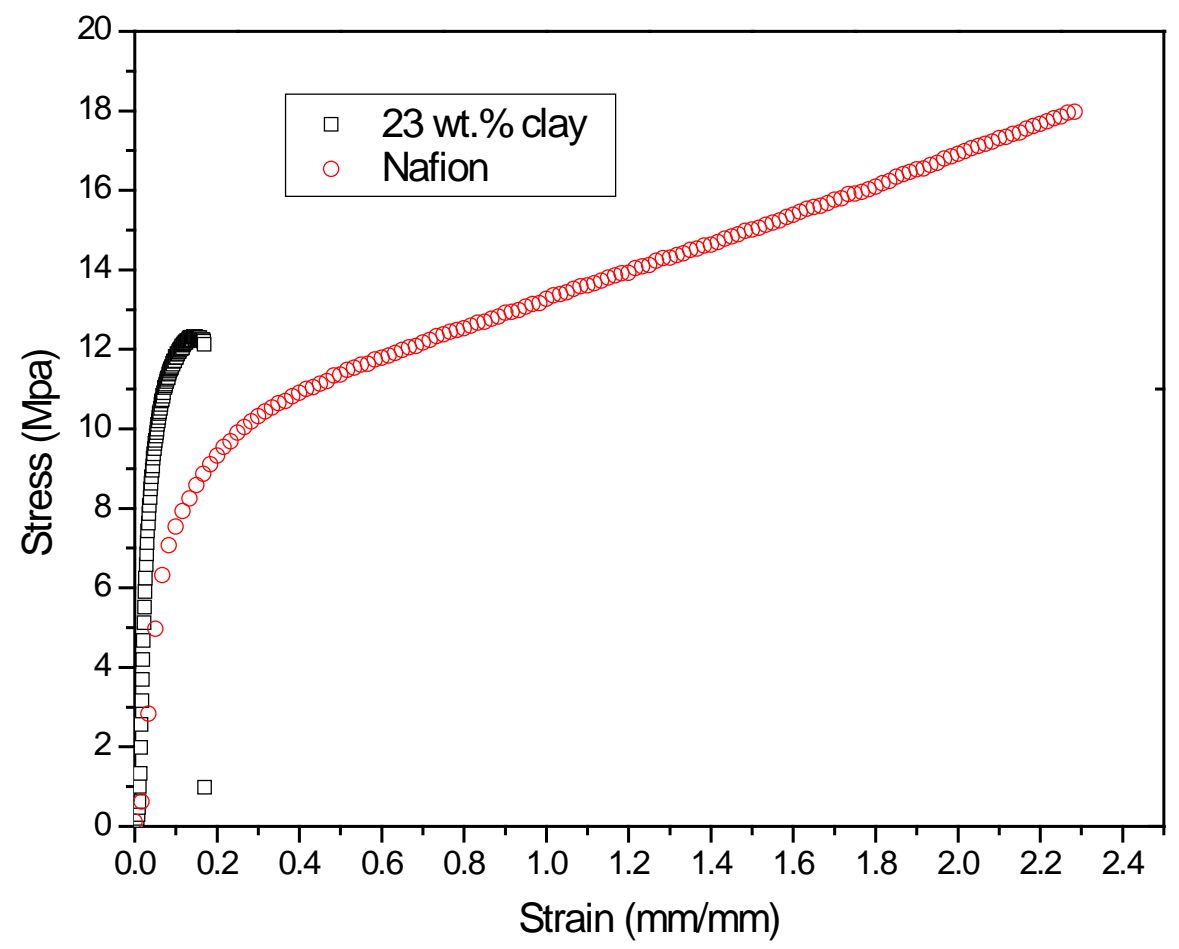

Figure 11. Stress-strain curves of Nafion and 23 wt\% clay-Nafion membranes. 


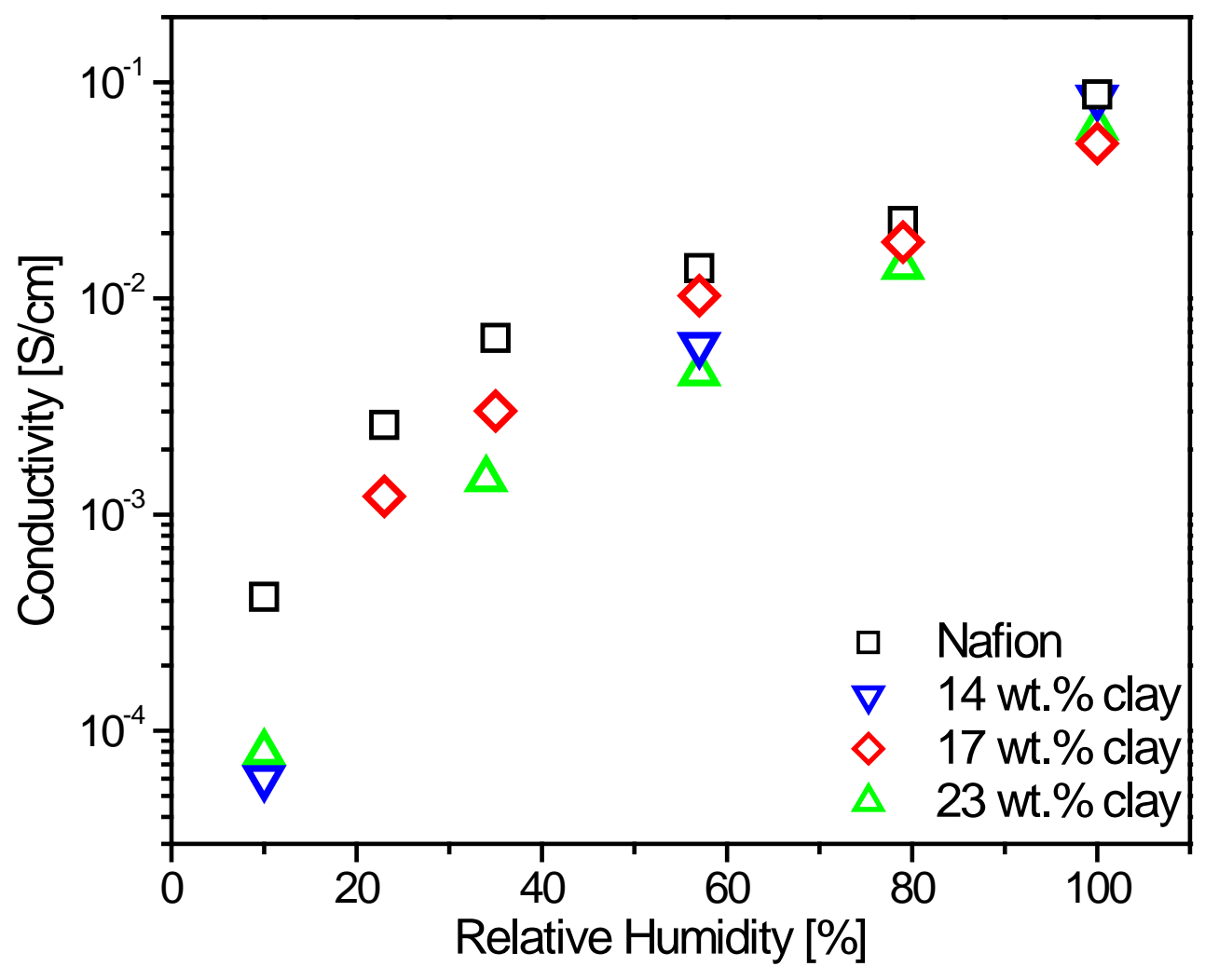

Figure 12. Ionic conductivity vs. relative humidity [\% RH] for Nafion and Nafion clay hybrid membranes 
a)

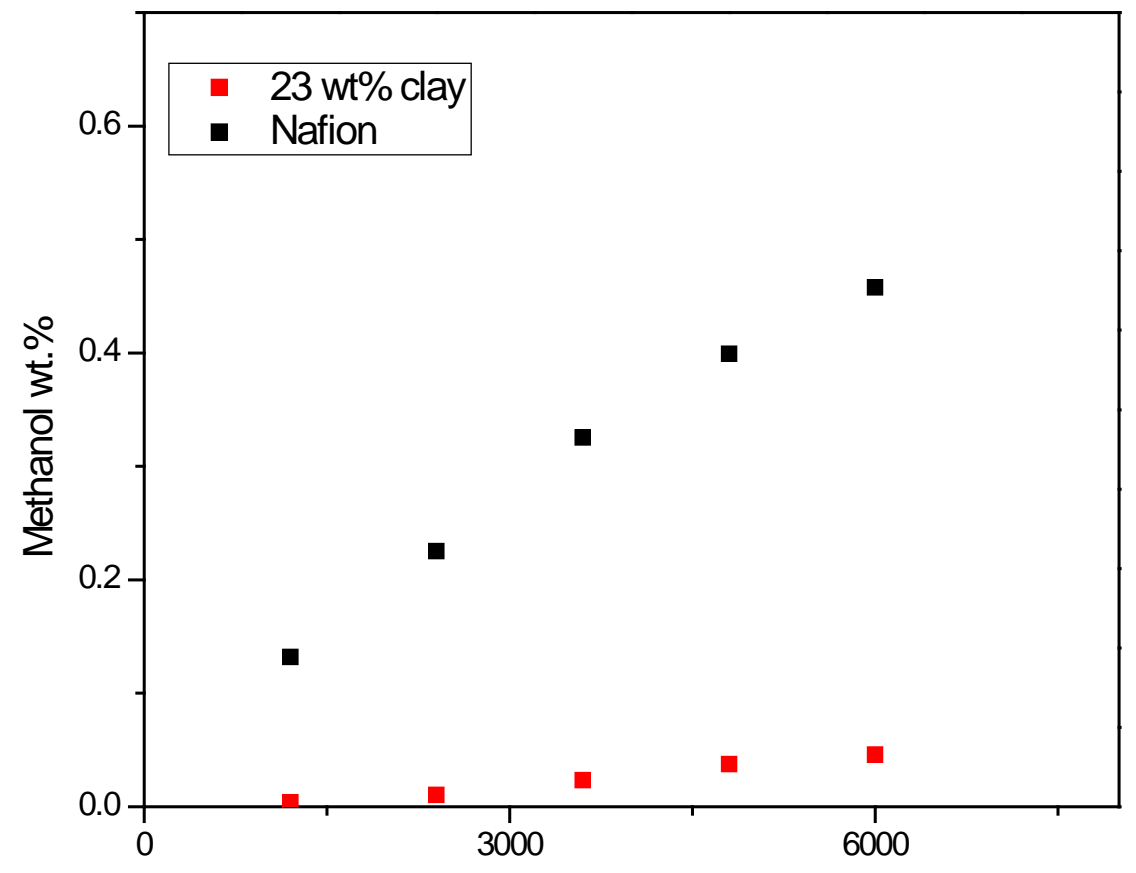

b)

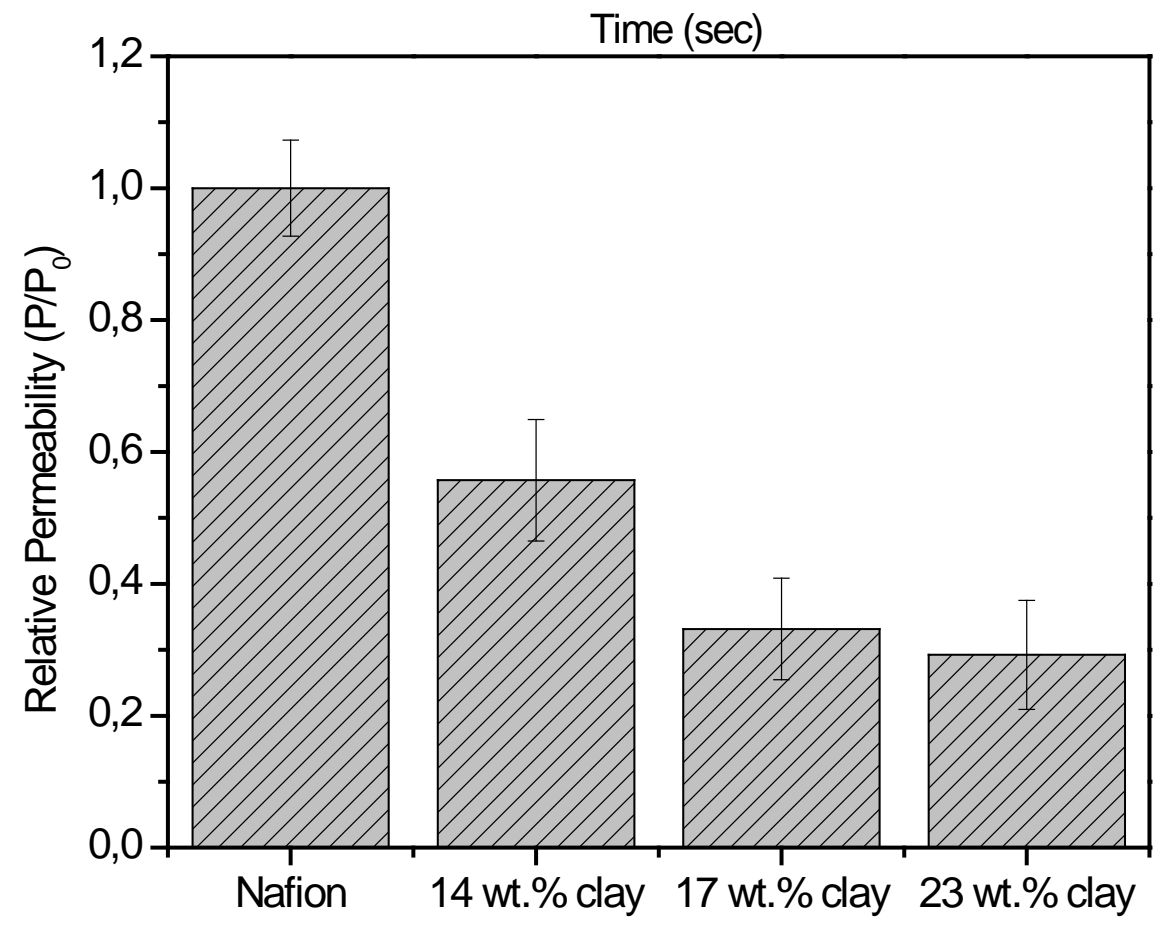

Figure 13. a) Methanol concentration (wt.\%) at the permeate cell as a function of time for pure Nafion and 23wt\% nanocomposite membranes.

b) Relative Permeability of Nafion and Nafion-clay hybrid membranes 


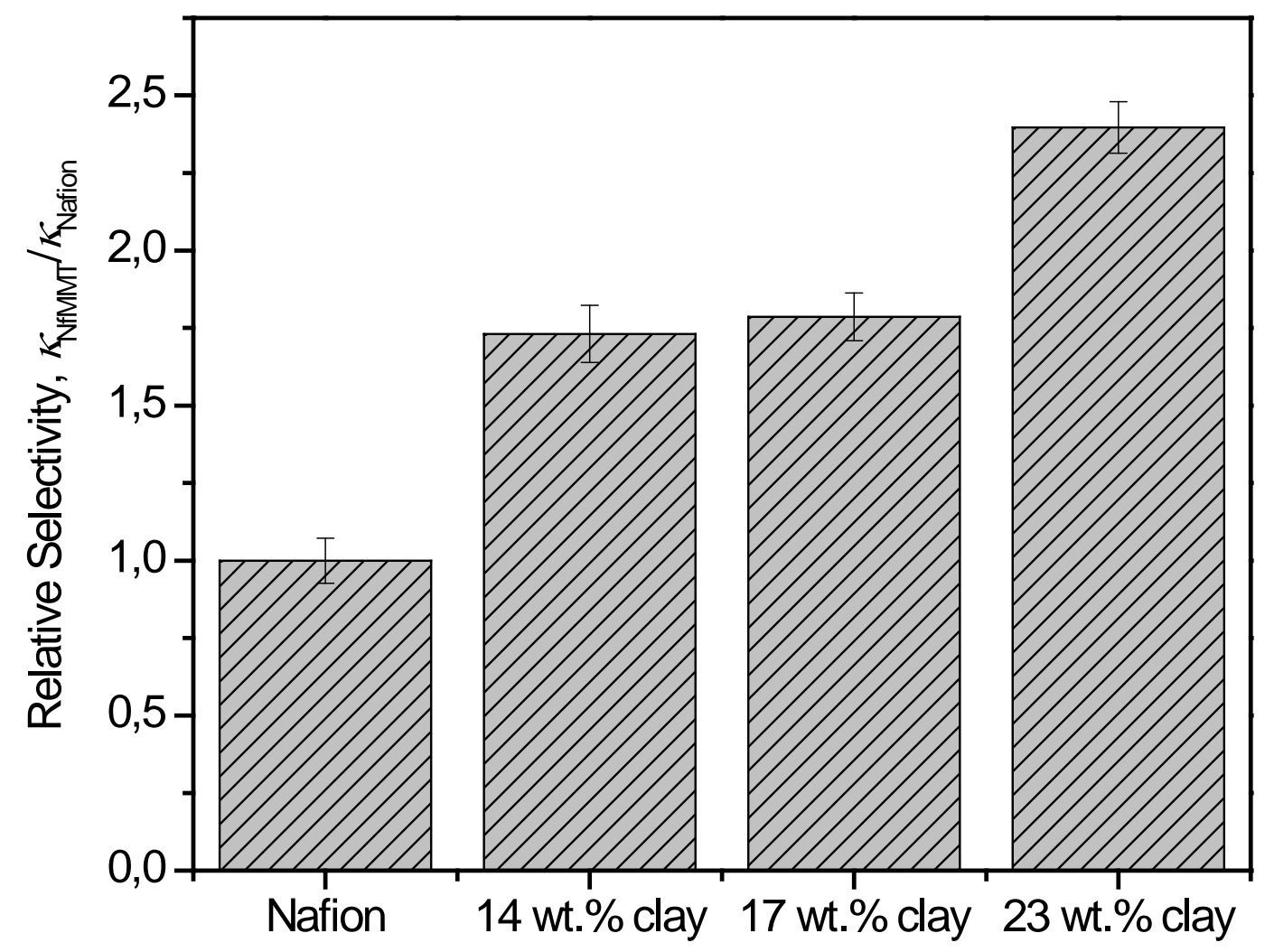

Figure 14. Relative Selectivity of Nafion and Nafion-clay hybrid membranes 